\title{
Safeguards Guidance
} Document for Designers of Commercial Nuclear Facilities: International Nuclear Safeguards Requirements and Practices for Uranium Enrichment Plants

Philip C. Durst

Brent McGinnis

James Morgan

Michael J. Whitaker

October 2009

The INL is a U.S. Department of Energy National Laboratory operated by Battelle Energy Alliance

Idaho National 
INL/EXT-09-16907

\title{
Safeguards Guidance Document for Designers of Commercial Nuclear Facilities: International Nuclear Safeguards Requirements and Practices for Uranium Enrichment Plants
}

${ }^{1}$ ORNL

\author{
Philip C. Durst \\ Brent McGinnis ${ }^{1}$ \\ James Morgan ${ }^{1}$ \\ Michael J. Whitaker ${ }^{1}$
}

October 2009

Idaho National Laboratory
Idaho Falls, Idaho 83415

http://www.inl.gov

Prepared for the

U.S. Department of Energy

Office of Nuclear Energy

Under DOE Idaho Operations Office

Contract DE-AC07-05ID14517 


\section{DISCLAIMER}

This information was prepared as an account of work sponsored by an agency of the U.S. Government. Neither the U.S. Government nor any agency thereof, nor any of their employees, makes any warranty, expressed or implied, or assumes any legal liability or responsibility for the accuracy, completeness, or usefulness, of any information, apparatus, product, or process disclosed, or represents that its use would not infringe privately owned rights. References herein to any specific commercial product, process, or service by trade name, trade mark, manufacturer, or otherwise, does not necessarily constitute or imply its endorsement, recommendation, or favoring by the U.S. Government or any agency thereof. The views and opinions of authors expressed herein do not necessarily state or reflect those of the U.S. Government or any agency thereof. 
(THIS PAGE INTENTIONALLY LEFT BLANK) 


\section{EXECUTIVE SUMMARY}

This report is the second in a series of guidelines on international safeguards requirements and practices, prepared expressly for the designers of nuclear facilities. The first document in this series is the description of generic international nuclear safeguards requirements and practices pertaining to all types of facilities. These requirements should be understood and considered at the earliest stages of facility design in keeping with the "Safeguards-by-Design" process and methodology. This will help eliminate the costly retrofit of facilities that has occurred in the past to accommodate nuclear safeguards verification activities, and will help the IAEA implement nuclear safeguards worldwide, especially in countries building their first nuclear facilities.

The following document summarizes the requirements for international nuclear safeguards implementation at enrichment plants of all types, prepared under the Safeguards-by-Design project. This work was funded by the U.S. Department of Energy (DOE) National Nuclear Security Administration (NNSA) Office of NA-243, in support of the NNSA Next Generation Safeguards Initiative. The purpose of this document is to provide designers of nuclear facilities around the world with a simplified set of design requirements and the most common practices for meeting them. The foundation for these requirements is the international safeguards agreement between the country and the International Atomic Energy Agency (IAEA), pursuant to the Treaty on the Non-proliferation of Nuclear Weapons (NPT). Relevant safeguards requirements are also cited from the Safeguards Criteria for inspecting enrichment plants, found in the IAEA Safeguards Manual, Part SMC-8. While the Safeguards Manual is an internal IAEA document, knowledge of the specific requirements contained therein is valuable to the designers of enrichment plants, so that plants are constructed with the verification goals and measures of the IAEA in mind.

IAEA definitions and terms are based on the IAEA Safeguards Glossary - 2001 Edition. The most current specification for safeguards measurement accuracy is found in the IAEA document STR-327, "International Target Values 2000 for Measurement Uncertainties in Safeguarding Nuclear Materials," published in 2001. If the country in question has implemented an Additional Protocol to their safeguards agreement with the IAEA, additional verification measures can be utilized by the IAEA, which are also described in the following document.

For this guide to be easier for the designer to use, the requirements have been restated in plainer language per expert interpretation using the source documents noted. The safeguards agreement is fundamentally a legal document. As such, it is written in a legalese that is understood by specialists in international law and treaties, but not by most outside of this field, including designers of nuclear facilities. For this reason, many of the requirements have been simplified and restated. However, in all cases, the relevant source document and passage is noted so that readers may trace the requirement to the source. This is a helpful living guide, since some of these requirements are subject to revision over time. More importantly, the practices by which the requirements are met are continuously modernized by the IAEA and nuclear facility operators to improve not only the effectiveness of international nuclear safeguards, but also the efficiency. As these improvements are made, the following guidelines should be updated and revised accordingly. 


\section{ACKNOWLEDGEMENTS}

Funding for the preparation of this document was provided by the U.S. DOE NNSA Office of International Regimes and Agreements (NA-243) under the Safeguards-by-Design Project, and in support of the NNSA Next Generation Safeguards Initiative (NGSI). The authors wish to thank the Office of NA-243 for their support and guidance in compiling the document. The authors also wish to thank Ms. Miriam Ogden for administrative support and Mr. Quinn Grover at INL for editing and preparing the final document. 


\section{CONTENTS}

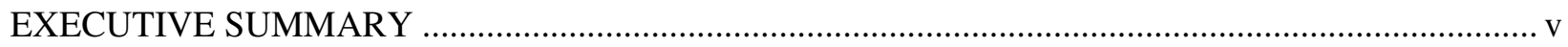

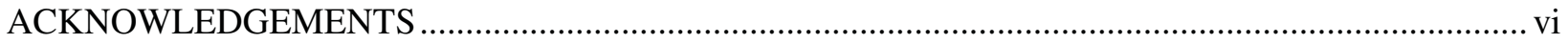

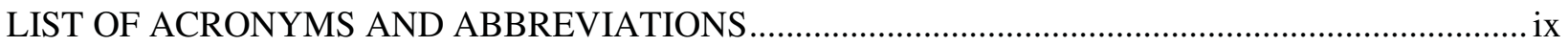

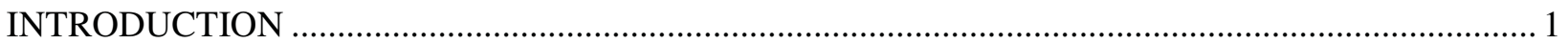

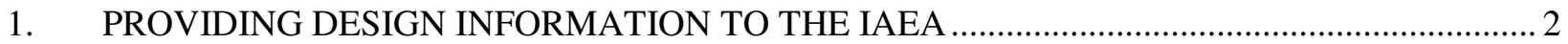

2. DEFINING NUCLEAR MATERIAL BALANCE AREAS (MBA) AND KEY

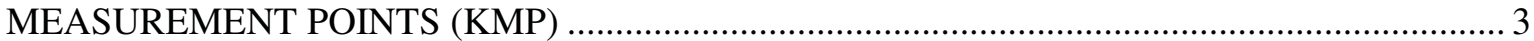

3. SAFEGUARDS OBJECTIVES IN AN ENRICHMENT PLANT ….......................................... 3

4. FUNDAMENTAL SAFEGUARDS MEASURES …............................................................. 4

5. PREPARING SUBSIDIARY ARRANGEMENTS (FACILITY ATTACHMENTS)..................... 5

6. VERIFICATION OF NUCLEAR MATERIAL AND INVENTORY .......................................... 6

7. NUCLEAR MATERIAL VERIFICATION PRACTICES …...................................................... 7

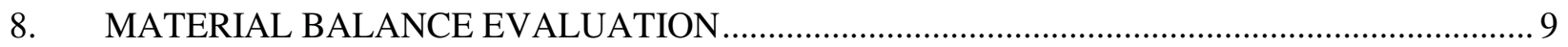

9. DESIGN INFORMATION EXAMINATION AND VERIFICATION (DIE/DIV) ........................ 9

10. CONFIRMING THE ABSENCE OF FACILITY MISUSE AND HEU PRODUCTION .............. 11

11. NUCLEAR MATERIAL ACCOUNTING AND OPERATING RECORDS................................. 12

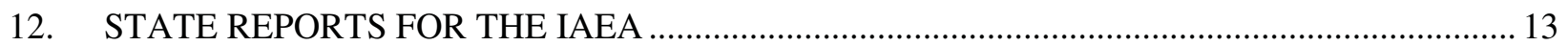

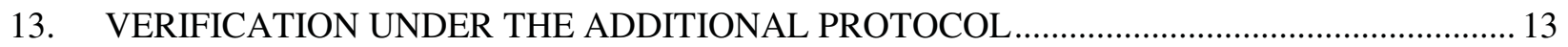

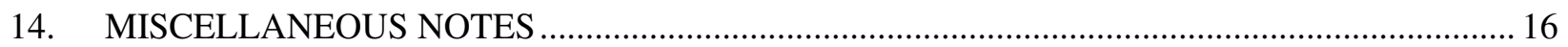

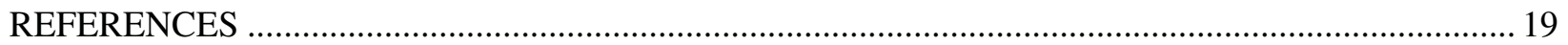

\section{FIGURES}

Figure 1: Layout of Material Balance Areas (MBAs) and Key Measurement Points (KMP) for a Typical Enrichment Plant. 
(THIS PAGE INTENTIONALLY LEFT BLANK) 


\section{LIST OF ACRONYMS AND ABBREVIATIONS}

3DLR (IAEA) 3-Dimensional Laser Range Finder

AP

(IAEA) Additional Protocol (to the safeguards agreement)

BOG

(IAEA) Board of Governors

CA

(IAEA) Complementary Access (under the Additional Protocol)

CDR

(Project Management) Conceptual Design Report

$\mathrm{C} / \mathrm{S}$

(IAEA) Nuclear Material Containment and Surveillance

CEMO

(IAEA) Continuous Enrichment Monitor

CHEM

(IAEA) Cascade Header Enrichment Monitor

CUMUF

(IAEA) Cumulative MUF (see also MUF below)

DA

Destructive (Chemical) Analysis

DI

(IAEA) Design information

DIE

(IAEA) Design Information Examination

DIQ

(IAEA) Design Information Questionnaire

DIV

(IAEA) Design information Verification

DOE U.S. Department of Energy

EFL

(NWS) Eligible Facility List

EOSS

(IAEA) Next Generation Electro-Optical Sealing System

ES

(IAEA) Environmental (Swipe) Sampling

F/W

$\mathrm{UF}_{6}$ Cylinder Feed and Withdrawal Stations

HEU

Highly Enriched Uranium (U-235 $\geqq 20 \%$ )

IAEA

International Atomic Energy Agency

ICR

(IAEA) Nuclear Material Inventory Change Report

ID

Identification

IIV

(IAEA) Interim Inventory Verification

IMCG

Inspector Multi-channel Gamma Analyzer (with germanium detector)

IMCN

Inspector Multi-channel Gamma Analyzer (with sodium-iodide detector)

INFCIRC/153 (IAEA) Model Comprehensive Safeguards Agreement

INFCIRC/540 (IAEA) Model Additional Protocol

ITV

(IAEA) International Target Values (for safeguards measurement accuracy)

KMP

(Nuclear Material Flow or Inventory) Key Measurement Point

LCBS

(IAEA) Load-Cell Balance System

LEU

Low Enriched Uranium (U-235 < 20\%) 
LFUA Limited-Frequency Unannounced Access (to the enrichment cascade hall)

MBA Nuclear Material Balance Area

MBP (IAEA) Material Balance Period

MBR (IAEA) Nuclear Material Balance Report

MMCA (IAEA) Mini Multi-channel (Gamma Spectra) Analyzer

MMCC (IAEA) Mini Multi-channel Gamma Analyzer (with cadmium-telluride detector)

MMCG (IAEA) Mini Multi-channel Gamma Analyzer (with germanium detector)

MMCN (IAEA) Mini Multi-channel Gamma Analyzer (with sodium-iodide detector)

MUF (IAEA) Material Unaccounted For

NDA Non-Destructive Assay

NGSS (IAEA) Next Generation Surveillance System

NNSA (U.S. DOE) National Nuclear Security Administration

NNWS (NPT) Non-Nuclear-Weapons State

NPT Treaty on the Non-Proliferation of Nuclear Weapons

NRC United States Nuclear Regulatory Commission

NU Natural Uranium (U-235 ca. $0.71 \%$ )

NWS (NPT) Nuclear-Weapons State

PIL (IAEA) Nuclear Material Physical Inventory Listing

PIV Physical Inventory Verification

PLEU Product/Low Enriched Uranium

SBD (NNSA) Safeguards-by-Design

SER (IAEA) State Evaluation Report

SIR (IAEA) Annual Safeguards Implementation Report

SNRI (IAEA) Short-Notice Random Inspection

SQ (IAEA) Significant Quantity of Fissile Material

SRD (IAEA) Shipper/Receiver Difference

SSAC State System of Accounting for and Control of Nuclear Material (National Nuclear Regulator)

U Uranium (chemical symbol)

U-235 Fissile Isotope of Uranium

U-235\% Uranium Enrichment (expressed as \% of uranium total)

U-238 Non-fissile Isotope of Uranium in nature

$\mathrm{UF}_{6} \quad$ Uranium Hexafluoride

ULTG (IAEA) Ultrasonic Thickness Gauge 
VACOSS (IAEA) Variable Coding Sealing System (electro-optical sealing system, also called VCOS)

VOA (NWS) Voluntary Offer Safeguards Agreement 
(THIS PAGE INTENTIONALLY LEFT BLANK) 


\section{Safeguards Guidance Document for Designers of Commercial Nuclear Facilities: International Nuclear Safeguards Requirements and Practices For Uranium Enrichment Plants}

\section{INTRODUCTION}

This report is the second in a series of guidelines on international safeguards requirements and practices, prepared expressly for the designers of nuclear facilities. The first document in this series is the description of generic international nuclear safeguards requirements pertaining to all types of facilities. ${ }^{1}$ These requirements should be understood and considered at the earliest stages of facility design as part of a new process called "Safeguards-by-Design." This will help eliminate the costly retrofit of facilities that has occurred in the past to accommodate nuclear safeguards verification activities, and will help the IAEA implement nuclear safeguards worldwide, especially in countries building their first nuclear facilities. The implementation of Safeguards-by-Design should also benefit the facility operator through the definition and potential joint-use of instruments that could be used in combination for nuclear criticality safety, process control, and nuclear safeguards. The implementation of the Safeguards-by-Design Process is described in more detail in the reference noted. $^{2}$

The following document summarizes the requirements for international nuclear safeguards implementation at enrichment plants, and was prepared under the Safeguards-by-Design project funded by the U.S. Department of Energy (DOE) National Nuclear Security Administration (NNSA), and in support of the NNSA Next Generation Safeguards Initiative. ${ }^{3}$ The purpose of this document is to provide designers of nuclear facilities around the world with a simplified set of design requirements and the most common practices for meeting them. The foundation for these requirements is the international safeguards agreement between the country and the International Atomic Energy Agency (IAEA), pursuant to the Treaty on the Non-proliferation of Nuclear Weapons (NPT), hereafter referred to as INFCIRC/153. ${ }^{4}$ Relevant safeguards requirements are also cited from the Safeguards Criteria for inspecting enrichment plants $^{\mathrm{a}}$, found in the IAEA Safeguards Manual, Part SMC-8, hereafter referred to as SMC-8. ${ }^{5}$ While the former is an internal IAEA document, knowledge of the specific requirements contained therein is valuable to the designers of enrichment plants, so that plants are constructed with the verification goals and measures of the IAEA in mind.

IAEA definitions and terms are based on the IAEA Safeguards Glossary - 2001 Edition, hereafter referred to as the Safeguards Glossary. ${ }^{6}$ The most current specification for safeguards measurement accuracy is found in the IAEA document STR-327, "International Target Values 2000 for Measurement Uncertainties in Safeguarding Nuclear Materials," published in 2001, hereafter referred to as the ITV.

If the country in question has implemented an Additional Protocol to their safeguards agreement with the IAEA, additional verification measures can be utilized by the IAEA, which will also be described in the following document. ${ }^{8}$ This source document will hereafter be referred to as the AP.

\footnotetext{
${ }^{a}$ NOTE: The IAEA Safeguards Criteria noted applies generically to the safeguarding of enrichment plants of all types throughout the world, subject to IAEA safeguards.
} 
For this guide to be easier for the designer to use, the requirements have been restated in plainer language per expert interpretation using the source documents noted. The safeguards agreement is fundamentally a legal document. As such, it is written in a legalese that is understood by specialists in international law and treaties, but not by most outside of this field, including designers of nuclear facilities. For this reason, many of the requirements have been simplified and restated. However, in all cases, the relevant source document and passage is noted so that readers may trace the requirement to the source. This is a helpful living guide, since some of these requirements are subject to revision over time. More importantly, the practices by which the requirements are met are continuously modernized by the IAEA and nuclear facility operators to improve not only the effectiveness of international nuclear safeguards, but also the efficiency. As these improvements are made, the following guidelines should be updated and revised accordingly.

\section{PROVIDING DESIGN INFORMATION TO THE IAEA}

Under their safeguards agreements with the IAEA, countries are required to provide information concerning nuclear material subject to safeguards and the features of facilities relevant to safeguarding this material. (INFCIRC/153, Para. 8).

This design information (DI) is prepared by the nuclear facility designer/builder or facility operator and transmitted through the State System of Accounting for and Control of Nuclear Material (SSAC) to the IAEA in the form of an IAEA design information questionnaire (DIQ).

The design information shall include: (INFCIRC/153, Para. 43).

- Identification of the facility, stating its general character, purpose, nominal capacity, geographic location, name, and address.

- Description of the general arrangement of the facility with reference to the form, location, and flow of nuclear material, and general layout of equipment that produces or processes nuclear material.

- Description of the facility features relevant to nuclear material accountancy (accountability), containment and surveillance $(\mathrm{C} / \mathrm{S})$.

- Description of the existing and proposed facility procedures for nuclear material accountancy and control, with reference to the nuclear material balance areas (MBAs) established by the facility operator, measurements of flow, and procedures for physical inventory taking.

Such information shall be provided as early as possible before nuclear material is introduced into a new facility. (INFCIRC/153, Para. 42).

Further, as per an IAEA Board of Governors decision in 1992, the country is to provide preliminary information on any new nuclear facility as soon as the decision is taken to construct or authorize the construction of the facility, and to provide additional safeguards-relevant information early in the stages of project definition. ${ }^{9}$ Facility design information is also to be provided for any safeguards-relevant changes in operating conditions throughout the facility life cycle. (Safeguards Glossary, Para. 3.28).

\section{Notes regarding Facility Design Information:}

1. Model DIQ responses have previously been prepared by U.S. DOE and provided to the IAEA through the United States Support Program, "Explanatory Notes and Model Responses for (IAEA) Design Information Questionnaires," ISPO-24, ISPO-Task C.9, May 1979, Vol. 2, "Model Responses for an Enrichment Facility Design Information Questionnaire." 
2. While the model responses aid facility operators and SSACs in submitting completed DIQs to the IAEA, they are 30 years old and need to be updated.

3. In the United States, the designated national authority (the U.S. NRC for NRC-licensed facilities and DOE for DOE regulated facilities) must provide a completed DIQ to the IAEA within 45 days of a nuclear facility being selected by the IAEA from the eligible facility list (EFL).

\section{Notes to Designers:}

1. The DIQ needs to be prepared by the facility operator, with input from the nuclear facility designer for new facilities, and be officially conveyed from the SSAC to the IAEA during the initial stages of conceptual design. Proper and timely coordination with the facility operator, SSAC, and IAEA is necessary to meet this requirement.

2. The majority of the information needed to complete the DIQ can be extracted from the designer's Conceptual Design Report (CDR) and facility layout and process flow drawings prepared during the Conceptual Design stage of the project.

\section{DEFINING NUCLEAR MATERIAL BALANCE AREAS (MBA) AND KEY MEASUREMENT POINTS (KMP)}

Facility design information is used by the IAEA to design the safeguards approach, determine nuclear material balance areas, and select key measurement and other strategic points, etc., for verifying the nuclear material flows and inventory. (INFCIRC/153, Para. 46)

An example of the proposed MBA and KMP layout for a typical enrichment plant is shown in Figure 1 at the end of this document.

\section{Notes to Designers:}

1. The facility operator typically defines the nuclear material balance areas (MBAs) and key measurement points (KMPs) based on models established for similar existing facilities and input from the IAEA. However, defining or changing these areas can impact the installation of safeguards instruments, surveillance, and electronic sealing systems. Any proposed changes to the facility MBAs and KMPs should involve the facility designers to fully understand the impact of the changes.

2. As an example of Point 1 above, the facility instrument design may include a network of components, such as computerized accountancy weighing scales, $\mathrm{UF}_{6}$ cylinder identification and tracking devices, non-destructive assay equipment, video surveillance and electronic sealing systems, and electronic "mailboxes" for submitting operator declarations regarding cylinder transfers, etc. The fuller integration of such instruments, potentially under a joint-use scenario by the facility operator and IAEA inspectors, could provide more effective process control, nuclear criticality safety, and safeguards for the facility operator and IAEA inspector.

3. If an instrumentation system is integrated for joint-use by both the facility operator and IAEA inspectors, the system must be capable of permitting independent verification by the IAEA. Proper and timely coordination with the IAEA is necessary to make certain that this requirement is met.

\section{SAFEGUARDS OBJECTIVES IN AN ENRICHMENT PLANT}

The objective of international nuclear safeguards is the timely detection of the diversion of significant quantities (SQs) of nuclear material, and the deterrence of such by the risk of early detection. (INFCIRC/153, Para. 28). 
Consequently, the international safeguards objectives are:

- Detect the diversion of $75 \mathrm{~kg}$ of U-235 in the form of natural uranium feed, depleted tails, or low enriched uranium (LEU, U-235 $<20 \%$ ), within one year of possible diversion.

- Detect the production and diversion of $25 \mathrm{~kg}$ of U-235 in the form of highly enriched uranium (HEU, U-235 $\geq 20 \%$ ), within one month.

- Detect possible facility misuse, or use of the facility for undeclared processing, including the presence of undeclared uranium and/or enrichment activities, reconfiguration of the cascade hall to produce and withdraw uranium hexafluoride $\left(\mathrm{UF}_{6}\right)$, and undeclared feed of uranium to the process.

(Safeguards Glossary, Para. 3.14, 3.15, and 3.20).

\section{Notes to Designers:}

1. The international goals for detecting a nuclear material diversion are the basis for defining the required nuclear safeguards measures and verification frequency and accuracy. The designer needs to involve safeguards specialists during the earliest stages of conceptual design to make certain that the evolving facility design will be amenable to domestic and international safeguards requirements.

2. The facility operator, designer, and SSAC should communicate with the IAEA on a regular basis during the design and construction of the facility to address the specific IAEA safeguards objectives and needs, especially in the early stages of facility design.

\section{FUNDAMENTAL SAFEGUARDS MEASURES}

Nuclear material accountancy (accountability) shall be the safeguards measure of fundamental importance, with C/S as important complementary measures. (INFCIRC/153, Para. 29).

Enrichment plants subject to IAEA safeguards are inspected on monthly pre-scheduled inspections for interim inventory verification (IIV) or on short-notice random inspections (SNRI) scheduled 3 to 6 times per year. The IAEA also conducts at least one physical inventory verification (PIV) per year, which, depending on the size of the plant, may require 10 IAEA inspectors over five working days. The primary safeguards measures used are: comparison of the operator's declared records for $\mathrm{UF}_{6}$ receipts, transfers, inventory, and shipments versus the inspector's observations and random verification of the same. The inspectors use statistically based random sampling to verify the uranium and U-235 flows and inventory by destructive and nondestructive analysis (DA and NDA). Inspectors also use tamper-indicating seals to secure verified $\mathrm{UF}_{6}$ and surveillance cameras as permitted by the subsidiary arrangements and facility attachment, especially during the PIV, to detect the possible substitution of $\mathrm{UF}_{6}$ cylinders.

\section{Notes to Designers:}

1. The designer needs to provide space for the safeguards verification activities that will be performed, as well as space and utilities for any permanently installed safeguards instruments.

2. The designer needs to allocate a controlled and dedicated space for storage of resident IAEA equipment, including portable equipment and computers. Currently, the space required is comparable to a large utility closet, approximately $4 \mathrm{X} 4 \mathrm{~m}(12 \mathrm{X} 12$ feet). However, as more IAEA equipment is permanently installed, such as the Continuous Enrichment Monitor (CEMO), access to this equipment by the IAEA and placement of the associated 19-inch $(50 \mathrm{~cm})$ wide data collection instrument cabinets needs to be considered by the designer. 
3. In an enrichment plant, the IAEA typically uses portable nondestructive instruments to verify the uranium and U-235 content of the natural feed, depleted tails, and enriched product cylinders. This verification is typically performed in the cylinder storage area. Also, the design of the cylinder storage array or racks, especially for depleted tails cylinders, needs to permit access to all cylinders for random verification and re-verification. New electronic or electro-optical techniques that permit the rapid inventorying of large groups of stored cylinders should be considered by the designer to aid inventory taking and verification by the facility operator, as well as the IAEA.

4. The IAEA verifies the gross weight of selected cylinders. For this purpose they may use a portable load-cell balance system (LCBS), or they may request to verify the electronic signal output from the facility operator's cylinder accountancy scales, and/or feed and withdrawal station load cells. If the latter is the case, the facility designer will need to design independent access to the instrument checkpoints as noted. This will also need to be coordinated with the IAEA in order to satisfy the IAEA requirements for joint-use of instruments for safeguards purposes.

5. If any IAEA safeguards equipment is to be permanently installed, such as the continuous enrichment monitor (CEMO), the designer will need to anticipate the instrument space, utility, and service requirements, which can be provided by the IAEA. The designer should note that the IAEA typically specifies a very heavy tamper-resistant interface cable between the safeguards instrument and data collection cabinet. The designer should know the specifications for this tamper-resistant cable, which the IAEA can provide.

6. The IAEA occasionally uses video surveillance in enrichment plants. Typically, this is not permitted by the facility operator or national authorities in the enrichment cascade halls. However, the use of portable or temporary surveillance by the IAEA is common during the annual Physical Inventory Verification (PIV), especially to monitor the movement of cylinders to and from the Feed and Withdrawal Stations. With this in mind, the designer should allocate space for the temporary placement of these surveillance systems, so as not to interfere with the operator's or IAEA inspector's activities. The placement of any IAEA video surveillance or electronic sealing systems (VACOSS and EOSS) needs to be coordinated with the facility operator, SSAC, and the IAEA.

\section{PREPARING SUBSIDIARY ARRANGEMENTS (FACILITY ATTACHMENTS)}

The IAEA and the country shall make subsidiary arrangements (to the Safeguards Agreement), which shall specify in detail how the IAEA is to fulfill its safeguards responsibilities under the Safeguards Agreement in an effective and efficient manner and how the procedures laid down in the Agreement are to be applied. The country shall promptly provide the IAEA with the information required for completing the subsidiary arrangements. (INFCIRC/153, Para. 39 and 40).

Subsidiary arrangements consists of a general part, applicable to all common nuclear activities of the country concerned, and a facility attachment, prepared for each facility in the country, which describes arrangements specific to that facility. One facility attachment may cover a group of facilities, in cases where several facilities are located in the same building, or share a common store or stores, (i.e. multi-unit reactor complexes). (Safeguards Glossary, Para. 1.26).

The facility operator, SSAC, and IAEA all participate in the preparation of facility attachments for a facility subject to IAEA safeguards and international inspection. Typically, the IAEA prepares the initial facility attachment, based on established models for existing facilities, which is then negotiated between the facility operator, SSAC, and IAEA until it is finalized. Facility attachments can be quite detailed and specify what instruments and equipment the IAEA will use, how frequently they will be used, the type of safeguards data and samples to be collected, where video surveillance or radiation monitoring equipment 
will be used, etc. Designers of nuclear facilities must work closely with facility operators and the SSAC to provide input into the preparation of facility attachments to facilitate the IAEA implementation of nuclear safeguards.

The facility attachment shall specify: (INFCIRC/153, Para. 32).

- A safeguards measurement system for the determination of quantities of nuclear material received, transferred, inventoried, and shipped

- Evaluation of measurement accuracy and estimates of uncertainty

- Procedures for reviewing and evaluating shipper/receiver differences (SRD)

- Procedures for taking the physical inventory

- Procedures for evaluating accumulations of unmeasured (un-measurable) inventory and unmeasured (un-measurable) losses

- A system of records and reports showing the inventory and inventory changes for each nuclear material balance area (MBA)

- Provisions to ensure that the accounting procedures and arrangements are being operated correctly

- Procedures for submitting relevant state reports to the IAEA.

\section{Notes to Designers:}

1. The facility designer needs to provide input to the facility operator during the preparation of the facility attachment, as discussed between the facility operator, SSAC, and IAEA. During this process, the IAEA can potentially identify new safeguards requirements that the designer was not aware of or misunderstood during the early stages of conceptual design. Consequently, the IAEA may request changes that could impact the facility design and construction. For this reason, discussion of the preliminary facility attachment between the facility operator, SSAC and/or national authority, and the IAEA is recommended at the earliest stages of conceptual design and during construction.

2. It is important for the facility operator and designer to be forthcoming to provide the information noted above to permit the IAEA the ability to implement effective international safeguards. It is also important to provide only the data that is relevant to that activity. The designer must also be mindful of the proprietary and sensitive nature of facility design information for enrichment plants, especially regarding the enrichment equipment, such as gas centrifuges, gaseous diffusers, aerodynamic separators, etc. This is discussed in more detail in the Section on Design Information Examination and Verification (DIE/DIV).

\section{VERIFICATION OF NUCLEAR MATERIAL AND INVENTORY}

The IAEA shall establish a unified inventory of nuclear material in the country, subject to safeguards under the agreement. (INFCIRC/153, Para. 41).

The design of nuclear facilities must allow the IAEA to determine the total amount of uranium and U235 in the facility to within an acceptable material-unaccounted-for (MUF) limit, or within established international target values (ITV) for safeguards measurement accuracy. Ideally, the domestic regulator defines these requirements into codified laws that ensure that enrichment plants have the means to meet the international requirements. This includes specifying the acceptable measurement limits at key measurement points, specifying MUF and cumulative material-unaccounted-for (CUMUF) limits for defined material balance periods (MBPs), and identifying corrective action if any of these limits are exceeded. 
For enrichment plants, the IAEA verifies nuclear material to the following criteria: (SMC-8).

- Receipts of $\mathrm{UF}_{6}$ natural feed cylinders are verified by random selection in accordance with the IAEA's sample algorithm, and are verified by DA, NDA, and weighing of the cylinder to a $50 \%$ detection probability. Cylinders are item counted and randomly cross-checked for ID.

- Stored inventory of natural feed, depleted tails, and enriched product cylinders are verified at the time of the interim inventory verification (IIV), as noted above.

- Cylinders containing heels are randomly verified to a $50 \%$ detection probability for radiation attribute (using the HM-4 or HM-5) and by weighing.

- $\mathrm{UF}_{6}$ cylinders transferred to and from the process are verified as noted above for receipt of $\mathrm{UF}_{6}$ cylinders. Typically, these cylinders are verified during the IIV or SNRI as they are declared and presented to the inspectors in the cylinder storage area.

- Sealed cylinders are inspected and verified for the absence of tampering by the random replacement of tamper-indicating seals.

- All or some of the above verification activities may be performed during the annual physical inventory verification (PIV). At the time of the PIV, the nuclear material in the facility is verified to the greatest extent possible, with an increase in detection probability and sample size. $\mathrm{UF}_{6}$ feed and withdrawal stations, chemical traps, cold traps, waste storage, and in some cases the cascade halls, are verified with portable instruments, as noted above.

\section{Notes to Designers:}

1. Facility designers should consider the need to measure and account for uranium and U-235 more accurately in enrichment plants, particularly in the cold traps, chemical traps, and uranium waste streams and handling system. More precise knowledge of the uranium and U-235 content of the waste stream will reduce the MUF and CUMUF values below action thresholds. The chemical and cold traps and uranium waste handling system design should consider a means for verification by nondestructive assay (NDA), which could include inspection ports for a portable system, or permanently installed detectors or load-cells.

2. Facility operators and designers should consider the use of an NDA system to verify the uranium and U-235 content of uranium waste drums and packaged spent chemical trap media containing uranium.

\section{NUCLEAR MATERIAL VERIFICATION PRACTICES}

The equipment used by the IAEA to perform safeguards verification activities in an enrichment plant is described in the references noted. ${ }^{10,11}$ The IAEA performs the following verification activities to implement the requirements noted in Section 6 to safeguard an enrichment plant:

- $\mathrm{UF}_{6}$ feed cylinders receipts verification may be done once or several times per year, depending on how often the enrichment plant receives feed.

- IAEA inspectors typically use an LCBS, which is a portable weighing instrument, to independently verify the accuracy of the operator's accountancy scale. It is accurate to within \pm 1 to $5 \%$ of total weight, depending on the range of the LCBS.

- In some new plants, the IAEA has proposed connecting to separate instrument signal output ports to permit independent verification of the facility operator's electronic accountancy scales and load cells on the $\mathrm{UF}_{6}$ feed and withdrawal stations. 
- Samples for DA are normally taken during the course of filling the cylinder, although they may also be taken during the IIV or SNRI if a sampling cart is used.

- IAEA inspectors use the mini multi-channel gamma analyzer with germanium detector (MMCG), mini multi-channel gamma analyzer with sodium-iodide detector (MMCN), inspector multi-channel gamma analyzer with sodium-iodide detector (IMCN), or inspector multi-channel gamma analyzer with germanium detector (IMCG) portable instruments to verify the uranium enrichment in natural feed, depleted tails, and enriched product cylinders. The cylinders are randomly weighed and assayed to determine total uranium and U-235 content in the cylinder. Inspectors also verify the cylinder wall thickness using an ultrasonic thickness gauge (ULTG), since the nondestructive assay depends on wall thickness.

- $\mathrm{UF}_{6}$ cylinders transferred to and from the feed and withdrawal stations (i.e., process) are typically verified during the IIV or SNRI, as they are declared and presented to the inspectors in the cylinder storage area.

- The IAEA replaces hundreds of seals during the PIV, particularly to verify the large and accumulating population of sealed tails cylinders. To minimize this effort, the IAEA has proposed the sealing of groups or clusters of cylinders using remotely monitored variable coding sealing system (VACOSS) or EOSS seals.

\section{Notes for Designers:}

1. The designer needs to provide space for the safeguards verification activities that will be performed, as well as space and utilities for any permanently installed safeguards instruments. The Continuous Enrichment Monitor (CEMO) is an example of a permanently installed instrument used by the IAEA to detect the presence of HEU in product headers in an enrichment plant. Although it has had limited field use, the expanded use of installed "Go/No Go" HEU monitors and detectors by the IAEA is likely. Permanently installed and unattended $\mathrm{UF}_{6}$ cylinder identification and verification portal monitors are also being considered for some facilities. The facility operator and designer should maintain an active dialog with the SSAC, national authorities, and IAEA, regarding the development of installed equipment that could be used jointly by the operator and IAEA inspectors.

2. In an enrichment plant, the IAEA typically uses portable NDA instruments to verify the uranium and U-235 content of the natural feed, depleted tails, and enriched product cylinders. This verification is most often performed in the cylinder storage area.

3. The IAEA verifies the gross weight of selected cylinders. For this purpose they may use a portable LCBS, or they may request to verify the electronic signal output from the facility operator's cylinder accountancy scales, and/or feed and withdrawal station load cells. If the latter is the case, the facility designer will need to design independent access to the instrument checkpoints as noted. This will also need to be coordinated with the IAEA in order to satisfy the IAEA requirements for joint-use of instruments for safeguards purposes.

4. If any IAEA safeguards equipment is to be permanently installed, such as the CEMO, the designer will need to anticipate the instrument space, utility, and service requirements, which the IAEA can provide. The designer should note that the IAEA typically specifies a very heavy tamper-resistant interface cable between the safeguards instrument and data collection cabinet. The designer needs to be aware of the specifications for this tamper-resistant cable, which the IAEA can provide.

5. To facilitate IAEA sample taking for DA, the designer should specify the color coding and labeling of tubing or piping from $\mathrm{UF}_{6}$ samplers to the point of origin.

6. The designer should consider arrangements to permit group sealing large arrays of depleted tails cylinders, which number in the hundreds and thousands and are generally stored on site at the 
enrichment plant. This should be coordinated with the IAEA to confirm that it will meet their safeguards requirements. Proposed methods include: providing sealing fixtures and hardware to seal groups of cylinders, sealing the access doors to cylinder storage rooms, and/or installing containment/surveillance equipment to detect the entry or removal of cylinders.

\section{MATERIAL BALANCE EVALUATION}

Nuclear facilities design must allow the IAEA to determine the total amount of uranium and U-235 in the facility to within an acceptable MUF limit or within established ITV for safeguards measurement accuracy. The IAEA compares differences between the declared shipper and receiver values for the uranium and U-235 content of the $\mathrm{UF}_{6}$ cylinders to determine the SRD. This is evaluated with the MUF and the running cumulative value of this statistic, or CUMUF. If these approach $75 \mathrm{~kg}$ of U-235 (in the form of LEU), the IAEA may request additional verification activities, including re-verifying $\mathrm{UF}_{6}$ cylinders and verifying uranium holdup in the enrichment cascade halls, chemical traps, cold traps, and waste transfers. If these metrics continue to equal or exceed $75 \mathrm{~kg}$ of U-235, the IAEA may declare a "Safeguards Anomaly" and could report the issue in the IAEA Annual Safeguards Implementation Report (SIR) and to the IAEA Board of Governors, seeking international support and corrective action.

\section{Notes for Designers:}

1. The facility should be designed to minimize the hold-up of uranium in the enrichment cascade hall, $\mathrm{UF}_{6}$ handling equipment, and process ventilation equipment, as well as minimize the potential for accidental release of $\mathrm{UF}_{6}$ and other compounds of uranium, especially at the $\mathrm{UF}_{6}$ Feed and Withdrawal Stations. The designer should also consider the need to access and assay this process equipment with portable NDA equipment to resolve potential inventory accounting issues.

2. The IAEA evaluation of the MUF, CUMUF, and SRD is independent and in principle does not involve the facility designer. However, these metrics do depend upon the facility design. The facility operator will declare and verify the receipt of $\mathrm{UF}_{6}$ cylinders, based on cylinder weighings performed using the accountancy scales and destructive analysis samples, as performed by the operator. Consequently, the accountancy scales need to be very accurate, normally on the order of $\pm 0.01 \%$ of total weight. The mass spectrometer that the operator's laboratory uses to verify the uranium enrichment and content of the $\mathrm{UF}_{6}$ received also needs to be accurate, since this will be the basis for confirming the amount of uranium and U-235 received. These factors influence the accuracy of the operator's declaration for nuclear material received, and hence affect the SRD, and the values of the MUF and CUMUF.

3. The IAEA has explored the possibility of using operator-declared flows for total uranium and U-235, based on mass and enrichment flow measurements of natural feed, depleted tails, and enriched $\mathrm{UF}_{6}$ product. Use of the facility operator's instruments for this purpose has been suggested. However, at this stage, this is strictly conceptual. In the future, though, it may be necessary for the IAEA to have access to these instruments under controlled conditions to improve nuclear safeguards in very large enrichment plants. This has the potential to control and reduce the MUF and CUMUF due to continuous measurement and greater instrument accuracy.

\section{DESIGN INFORMATION EXAMINATION AND VERIFICATION (DIE/DIV)}

As noted in Section 1, "Providing Design Information to the IAEA," the facility operator is obliged to provide safeguards relevant facility information, regarding the design and operation of the facility, through the SSAC to the IAEA, to permit the IAEA to effectively safeguard the nuclear material and 
facility. The IAEA performs Design Information Examination and Design Information Verification (DIE/DIV) activities, to verify that the facility is being constructed and operated as declared, i.e., that the function or capacity of the facility has not been altered. It is not the role of the IAEA to perform a Quality Assurance or Quality Control function during facility design and construction. However, the IAEA is entitled to safeguards relevant design and operating information to draw conclusions that the facility is being operated as declared by the facility operator and national authorities. It is also important for the designer to be mindful of the proprietary and sensitive nature of the enrichment plant and enrichment equipment design information, and take measures to protect that information considered sensitive or proprietary by the facility operator and national authorities. The following lists the key points relevant to the IAEA DIE/DIV activity:

- Design information (DI) that a country provides to the IAEA is examined and verified according to IAEA procedure. (SMC-8, Para. 11.1).

- DI is re-examined at least once per year in light of any facility modifications or changes in operating conditions, etc. (SMC-8, Para. 11.2).

- Periodic verification of design information is performed to confirm its continued validity. (SMC-8, Para. 11.3).

- Initial design information verification inside the cascade area will be performed as foreseen in the relevant facility attachments. (SMC-8, Para. 11.4).

- Over the life of an enrichment plant, the IAEA reviews, examines, and verifies the safeguards relevant design information. Typically this begins during the facility design and construction initiation.

\section{Notes regarding DIE/DIV:}

1. The IAEA may use considerable inspection resources to perform DIE/DIV of an enrichment plant during construction. These activities may be as frequent as quarterly or monthly, depending on the degree of construction activity and what requires verification.

2. While the national authorities, SSAC, and facility operator have concerns about sensitive and commercial technology, the IAEA needs to verify that the nuclear facility is being built or operated as declared, in order to determine that it is not being misused.

3. The secure control and acquisition of design information is very important for all parties. Typically, the IAEA keeps photos, drawings, and other design information that the national authorities consider sensitive at the facility in a secured enclosure under joint seal of the national authorities and the IAEA.

\section{Notes for Designers:}

1. It is useful to have a representative from the facility designer support the facility operator during the facility's DIE/DIV.

2. Sensitive facility design information that is not safeguards relevant need not be provided to the IAEA. Authorities from the SSAC, in discussion with the IAEA, can determine what is relevant. The IAEA does need, however, enough design information to confirm that the facility is being built and/or operated as declared.

3. The IAEA DOES NOT NEED to verify the sensitive internal design and construction and operating details of the high-speed gas centrifuge rotors, bearings, scoops, and housings. This information is considered highly sensitive for both the national authorities and the facility operator.

4. In newer facilities, the IAEA has been using a 3-Dimensional Laser Range Finder (3DLR), which is a modern electro-optical, laser-based survey tool for performing DIV. The computerized images 
created by the 3DLR are of very high resolution and capture intricate design details. Secure control of data acquisition and storage is very important.

5. The 3DLR is being combined with a "Gamma Camera," which has the potential to detect the presence of undeclared uranium processing or HEU in the facility.

6. The use of IAEA equipment for routine inspection and for DIE/DIV requires approval by the facility operator's Safety Group, as well as approval by the facility constructor's Safety Group, if the equipment is used to perform DIE/DIV of the facility while under construction. Fundamentally, this is the IAEA's concern, although the facility operator can liaise to ensure that the IAEA activities are performed in a manner mindful of the operating and construction environment - especially from the standpoint of industrial safety and radiation protection.

\section{CONFIRMING THE ABSENCE OF FACILITY MISUSE AND HEU PRODUCTION}

At facilities where access to the cascade areas is restricted, inspections are carried out within the cascade areas on an unannounced basis, and at times not predictable to the country, in order to confirm the absence of the unreported production of (HEU). (SMC-8, Para. 6.1).

This activity is termed a Limited Frequency Unannounced Access (LFUA) and is typically performed 4 to 14 times per year to detect in a timely manner, the possible reconfiguration of the cascade header piping in the cascade hall to produce and withdraw HEU.

During the LFUA, the following activities may be performed: (SMC-8, Para.6.2).

- Visual observation to detect unreported feed or withdrawal equipment in the cascade hall

- Visual observation to detect reconfiguration of the cascades in series

- NDA verification of cascade header piping to detect HEU production

- Collection of DA samples from the cascade hall to detect HEU production

- Environmental (swipe) sampling (ES) to detect the presence of HEU

\section{Notes regarding LFUA:}

1. Typically, the IAEA requests access to the cascade hall within 2 hours of notifying the national authorities (SSAC).

2. Depending on the country, an LFUA may or may not be permitted after normal working hours, on weekends, or company and national holidays. This depends on the arrangements the IAEA has made with the facility operator, SSAC, and national authorities.

3. In performing visual observation, the IAEA typically uses photo albums that show reference photographs of the cascade hall to detect changes. These photo albums contain sensitive design information and are normally kept at the facility in secured enclosures under joint seal of the national regulatory authorities and the IAEA.

4. The IAEA may use either the installed CEMO or the portable cascade header enrichment monitor (CHEM) to detect the presence of HEU. Both instruments require a radiation source that needs to be properly stored at the facility and replaced approximately every 2-3 years. 
5. While in principle the collection of DA samples from the cascade hall is specified in the IAEA Safeguards Criteria, it is seldom allowed or performed. Alternate sampling locations are selected, and other means are used, such as environmental sampling, to provide assurance that HEU is not being produced.

\section{Notes for Designers:}

1. The IAEA needs to confirm that the configuration of cascade header piping has not been altered to permit undeclared recycling of $\mathrm{UF}_{6}$ to produce $\mathrm{HEU}$ or undeclared removal of $\mathrm{UF}_{6}$ directly from the cascade hall. Consequently, the cascade header piping needs to be installed and clearly labeled to permit inspection at all locations. In some cases, this has been achieved by routing piping below floor level under removable and accessible hatch covers, or by running the header piping overhead in clear view. In general, the piping design should allow the IAEA inspector to trace the piping route from one location to another to detect undeclared reconfiguration of the piping.

2. Labeling and/or color coding of the following headers and lines is recommended to facilitate this activity: natural uranium feed, enriched $\mathrm{UF}_{6}$ product, depleted tails, cooling water in, cooling water out, instrument lines, compressed air, fire protection, electrical power, etc.

\section{NUCLEAR MATERIAL ACCOUNTING AND OPERATING RECORDS}

In accordance with the safeguards agreement with the IAEA and facility attachment, the facility operator must be able to produce accounting records for receipts, transfers, shipments, and inventory of $\mathrm{UF}_{6}$ in the enrichment plant. (INFCIRC/153, Para. 51-55).

These records must note the gross and net weights of natural feed, depleted tails, and enriched product $\mathrm{UF}_{6}$ and associated net weights of uranium and U-235, moved or stored. The basis for these accounting records maintained by the facility operator are the facility operating records. Consequently, the aforementioned values need to be clearly traceable to the operating records and method of measurement.

The system of measurements on which the records used for report preparation are based shall conform to the latest international standards or equivalent. (INFCIRC/153, Para. 55) Domestic regulations that require meeting this requirement are enforced by the national regulator.

For each MBA, the operator shall maintain accounting records to document the following: (INFCIRC/153, Para. 56 and 57).

- Inventory changes involving uranium and $\mathrm{U}-235$ in the form of $\mathrm{UF}_{6}$ or other compounds

- Determination of book inventory of uranium and U-235

- Measurement methods and results used to establish the physical inventory of uranium and U-235

- Adjustments and corrections made to inventory changes, book inventories, and physical inventories

- Date of inventory changes and associated source and receiving MBA.

The above shall show for each batch of $\mathrm{UF}_{6}$ the material identification, batch data, and source data.

For each MBA, the operator shall maintain operating records that include: (INFCIRC/153, Para. 58).

- Operating data used to establish changes in quantities and composition of nuclear material

- Data obtained from the calibration of tanks and instruments, sampling and analyses, measurement control procedures, and estimates of measurement error 
- Description of the procedure and preparations for the operator's physical inventory taking (PIT)

- Description of actions taken by the operator to determine cause and magnitude of accidental or unmeasurable losses of uranium or U-235.

\section{Notes for Designers:}

1. The facility must be adequately instrumented to allow the operator to make and maintain acceptable nuclear material accounting and operating records.

2. The design and/or selection of weighing systems, mass spectrometers, $\mathrm{UF}_{6}$ mass flow measurement, and control systems for the facility should meet or exceed the ITV for safeguards measurement accuracy.

3. The IAEA typically witnesses the calibration of the operator's instruments used to establish the operator's declaration for uranium and U-235 transfers and inventory, i.e., cylinder accountancy scales, mass spectrometers, and potentially, $\mathrm{UF}_{6}$ header mass and enrichment flow monitors.

4. Radioactive sources and calibration standards will need to be stored and controlled to permit the calibration of the facility operator's instruments and equipment on which the nuclear material accounting is based.

\section{STATE REPORTS FOR THE IAEA}

The country shall provide accounting reports to the IAEA at prescribed intervals regarding the nuclear material subject to safeguards at the enrichment plant. The reports shall be based on the operating records kept and maintained by the facility operator, as noted above. (INFCIRC/153, Para. 59-69).

The reports shall be as specified in INFCIRC/153 or the relevant safeguards agreement.

\section{Note for Designers:}

1. The state reports are prepared based on declarations from the facility operator, and indirectly, on the operating and accounting records. As such, they are traceable to the facility's instruments and measurement system. The designer should be aware that if the plant is not instrumented to the highest current international standard, it will negatively impact the quality of state reports submitted by the SSAC to the IAEA regarding safeguarding nuclear material at the facility.

\section{VERIFICATION UNDER THE ADDITIONAL PROTOCOL}

If the country in question has implemented a protocol additional to the safeguards agreement with the IAEA, modeled after INFCIRC/540, then the IAEA may use additional measures which are intended to strengthen the application of nuclear safeguards in the country. These include the following: (AP, Articles $2,3,4,5,6$, and 7$)$.

- Declaration of all nuclear sites in the country as a whole, with a map identifying each site and each facility on a site, together with a general description of each building, description of its function, and description of its contents.

- Declaration of specified nuclear fuel cycle related activities in the country that do not involve nuclear material, including research and development and nuclear fuel cycle related manufacturing activities listed in Annex-I of the AP. This also includes the manufacturing of 
centrifuge rotor tubes or the assembly of gas centrifuges, as well as the location and output of uranium mines.

- Declaration of the import or export of specified nuclear fuel cycle related equipment and nonnuclear material listed in Annex-II of the AP, including equipment for use in uranium enrichment plants. The declaration includes the exporter, importer, equipment type, identification, quantity, and intended location for end-use.

- Use of Complementary Access (i.e., IAEA inspector access to the facility at short-notice, complementary to the routine safeguards inspection) to any location on a nuclear site to assure the absence of undeclared nuclear material and activities. This also includes access to any location identified in the state's declaration under the AP to resolve apparent questions or inconsistencies in that information.

- Use of visual observation.

- Use of radiation detection equipment, measurement devices, and tamper-indicating seals.

- Use of location specific environmental (swipe) sampling (ES) at any place on a nuclear site, any location identified in the state's AP declaration, or any other location specified by the IAEA.

- Examination of relevant records and other objective measures.

The practical implications of the implementation of the AP is that the IAEA may announce a Complementary Access to sites and locations noted above, including enrichment plants, and use the verification measures noted, i.e., visual observation, radiation detection equipment, and environmental (swipe) sampling. This includes access to locations identified in the country's AP declaration, but not otherwise within the site of a safeguarded facility.

Complementary Access (CA) is normally granted to any place on the declared nuclear site identified by the IAEA within two hours of notification to the national authorities or SSAC, sought in conjunction with DIE/DIV activities, routine, or ad hoc inspections. In all other instances, the IAEA provides 24 hours notice to the SSAC.

The purpose of the CA is to detect any undeclared nuclear materials and/or activities, including activities inconsistent with the country's declared 10-year plan for development of its nuclear fuel cycle. In the case of enrichment plants, this means detecting indicators, anywhere on the site, of the undeclared feed of uranium to the process, undeclared production and removal of enrichment product, or presence and undeclared production of HEU. It also means assessing the consistency of the declared research and development not involving nuclear material, and use of facilities producing enrichment equipment, such as gas centrifuges, gaseous diffusers, and laser isotope separators, etc. In performing the CA, the IAEA may request access to any structure on the site, or even facilities adjacent to the site that the IAEA asserts are functionally linked to the enrichment plant site.

The national nuclear authorities, or SSAC, and the facility operator have the right to "manage" inspector access and prevent the dissemination of commercial and proliferation-sensitive information pertaining to the design of uranium enrichment equipment, and the process conditions under which this equipment operates. They can do so by declaring in advance the need for "managed access," in accordance with the AP. However, the facility operator and SSAC must identify this in advance when they submit the AP declaration for the site to the IAEA, in accordance with the requirements identified in the AP. They must also indicate what access is being "managed" and the reasons why. However, the use of managed access does not preclude the IAEA from conducting activities necessary to provide credible assurance of the absence of undeclared nuclear material and/or activities, including the resolution of 
questions regarding inconsistencies, or requests for clarification. If too great an effort is made to conceal equipment at the enrichment plant site, the IAEA may be unable to meet the objectives stated, which could potentially result in the matter being referred to the national nuclear authorities and the IAEA Board of Governors. In this case, typically a subsequent CA is announced to meet the original objectives, after the access arrangements and limitations have been clarified with the relevant parties and authorities.

The use of environmental sampling is as agreed with the country in question. If the facility operator and authorities cannot provide the IAEA with access to the location requested by the IAEA, to carry out location-specific environmental sampling, then they must make every reasonable effort to provide the IAEA with an alternate means to meet the objective of the CA.

\section{Notes for Designers:}

1. The need to protect sensitive design information during the CA is the same as during the LFUA and DIV activities, previously described. Sensitive design information pertinent to the enrichment equipment, such as gas centrifuge rotors, scoops, bearings, and magnetic drives, are normally protected by housing these components in a centrifuge enclosure.

2. Designers should consider provisions to protect or conceal the displays of process instruments that could potentially reveal process conditions or data that has not been agreed as data to be shared with the IAEA for the purpose of safeguards. Designers should also consider the 2-hour Complementary Access advance notification requirements in designing the enrichment plant - i.e. the enrichment plant should be designed so that if IAEA inspectors access it under a short-notice random inspection (SNRI) or Complementary Access, they will not have access to commercial and proliferationsensitive technology and information.

3. The IAEA must be able to walk through the facility and inspect safeguards relevant process equipment in all parts of the plant in order to meet the objectives to detect the presence of undeclared nuclear material and/or activities, using visual observation, radiation detection equipment, and environmental sampling. The designer should consider this when designing the layout and features to enter and access the facility.

4. Typically, the IAEA is allowed to inspect the enrichment plant $\mathrm{UF}_{6}$ cylinder storage areas, $\mathrm{UF}_{6}$ cylinder feed and withdrawal stations, and cascade enrichment halls upon request, although they may also request access to facilities on site that are declared for testing, manufacturing, and servicing enrichment separators and other enrichment equipment. Under the AP, the IAEA can request access to any place on the site of a safeguarded facility.

5. The IAEA has the right to conduct Complementary Access at research and development and enrichment equipment manufacturing locations not located on the site of a uranium enrichment plant, or other safeguarded nuclear site. The operators and designers of these facilities should be aware and consider this, and the need to protect commercial and proliferation-sensitive information in the design of these facilities as well. 


\section{MISCELLANEOUS NOTES}

While the aforementioned sections state requirements and provide guidance for the implementation of international nuclear safeguards in an enrichment plant, the following is a summary of additional best practices and points for the designer to consider:

1. The IAEA inspector must confirm the extent and capacity of the enrichment plant, particularly the size and extent of the uranium enrichment cascade hall. Consequently, it must be possible for the inspector to walk the hall, or halls, from end to end. It is also advisable that there not be any subbasements or other concealed spaces contiguous to the cascade halls that would attract attention as undeclared nuclear material processing areas.

2. The header piping routed to and from the cascade hall should be easily traceable and clearly color coded and labeled as to the contents.

3. Under current IAEA safeguards approaches, the use of video surveillance in enrichment plants is very limited, and is generally not permitted in the cascade hall, unless specifically permitted by the national authorities and SSAC. However, the IAEA does use video surveillance cameras during the PIV to monitor the movement of $\mathrm{UF}_{6}$ cylinders to and from the Feed and Withdrawal Stations, especially if the PIV is a "dynamic PIV," which does not require facility shutdown and cleanout. Space for the portable surveillance cameras needs to be provided that permits an unobstructed view of the loading zone of each Feed and Withdrawal Station. This design detail should be coordinated with the facility operator, SSAC, and IAEA.

4. Under current IAEA safeguards approaches, metal cap (or cup) seals remain the dominant tamperindicating device used by IAEA safeguards inspectors. Like the seals from the facility operator and domestic regulator, they are applied to the $\mathrm{UF}_{6}$ cylinder valve cover on the front end and drain plug on the back end of the cylinder. These seals need to be protected so that they are not accidentally removed, damaged, or exposed to severe weather that would damage the seal. The IAEA is also experimenting with other means of sealing large groups of static cylinders, especially the large stockpiles of depleted tails cylinders.

5. For verifying the uranium and U-235 involved in process flows and inventory, the IAEA typically uses portable NDA instruments on the declared cylinders typically presented in the cylinder storage building. It is also possible to verify the cylinders just prior to being loaded or removed from the Feed and Withdrawal Stations. However, it is generally easier and safer if this verification activity is performed in the cylinder storage building.

6. The IAEA verifies the gross weight of selected cylinders near the facility operator's accountancy scales so that they can compare the operator's measurement and declaration against the value for the cylinder gross weight verified by the IAEA.

7. Work is being performed to develop a more effective mass flow and enrichment monitor to measure the uranium and U-235 process flows in cascade header piping, as well as an unattended $\mathrm{UF}_{6}$ portal monitor that could be positioned to monitor enrichment of cylinders transferred to and from the Feed and Withdrawal Stations. Neither system has been demonstrated in an industrial facility, although, one or the other could potentially appear in future enrichment plants to enhance nuclear safeguards and process control.

8. Accountancy scales are typically located indoors near the traffic route to the Feed and Withdrawal Stations, to permit the weighing of cylinders transferred to and from the process. Typically, this is in the Cylinder Receipt and Dispatch, or Cylinder Storage Building. 
9. In a modern enrichment plant, $\mathrm{UF}_{6}$ cylinders are conveyed by transfer carts using rails on fixed routes, although fork-lift cylinder carriers are still in use. Because the transfer routes to and from the process are fixed, this allows the facility operator and safeguards inspector to monitor the cylinder traffic.

10. The safeguards continuity-of-knowledge of a cylinder is lost when the seal is damaged or accidentally removed. Previously verified cylinders, or cylinders verified at and shipped from another location, are sealed to preserve the safeguards continuity-of-knowledge. To prevent accidental removal, operating staff are taught to recognize and understand the importance of the seals of the domestic regulator and IAEA. Under certain circumstances, the operator can remove IAEA seals on sealed cylinders, provided that advanced notice is given to the IAEA and SSAC that the facility operator needs to process the sealed cylinder. However, in this case, the domestic authorities and IAEA are notified and adequate time is permitted to allow them to respond, regarding any concerns they may have, e.g., such as the cylinder must remain sealed pending confirmation of anomalous verification results. To further prevent the accidental damage or removal of seals, covers may be used to protect the seals and signs placed in the area, alerting operating staff of the presence and importance of the tamper indicating seals. 


\section{A Typical Enrichment Plant}

Material Balance Area (MBA) Layout With Key Measurement Points (KMP)

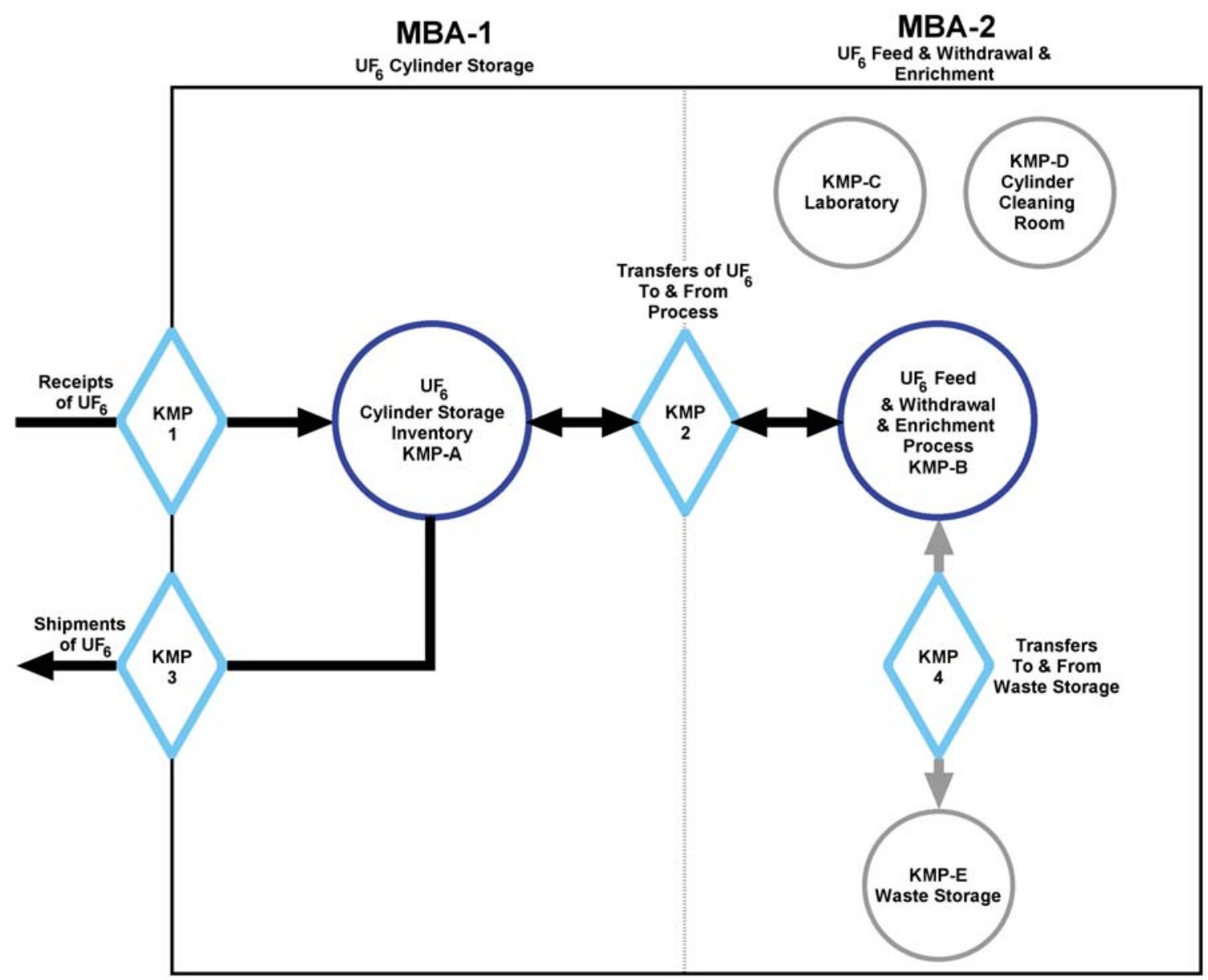

Figure 1: Layout of Material Balance Areas (MBAs) and Key Measurement Points (KMP) for a Typical Enrichment Plant. 


\section{REFERENCES}

1. Boyer, B. D., K. Thomas, P. C. Durst, and M. Mullen: "Safeguards-by-Design General Guidance," Los Alamos National Laboratory Report \# (pending), Los Alamos, New Mexico, October, 2009.

2. Bjornard, T., et al.: "Implementing the Safeguards-by-Design Process," U.S. DOE Idaho National Laboratory Report \# INL/EXT-09-17085, Idaho Falls, ID, October, 2009.

3. U.S. Department of Energy, National Nuclear Security Administration: Next Generation Safeguards Initiative, NNSA Office of Nonproliferation and International Security (NA-24), Washington, D.C., October, 2007.

4. International Atomic Energy Agency: The Structure and Content of Agreements between the Agency and States Required in Connection with the Treaty on the Non-Proliferation of Nuclear Weapons, INFCIRC/153 (corrected), Vienna, Austria, June, 1972.

5. International Atomic Energy Agency, Department of Safeguards: Safeguards Manual, Parts- SMI and SMC, Section SMC-8, "Enrichment Plants," Vienna, Austria, October, 2003. (IAEA Internal Document)

6. International Atomic Energy Agency: IAEA Safeguards Glossary - 2001 Edition, Vienna, Austria, 2002.

7. International Atomic Energy Agency: International Target Values 2000 for Measurement Uncertainties in Safeguarding Nuclear Materials, IAEA Report STR-327, Vienna, Austria, 2000.

8. International Atomic Energy Agency: Model Protocol Additional to the Agreement $(s)$ between State(s) and the International Atomic Energy Agency for the Application of Safeguards, INFCIRC/540 (corrected), Vienna, Austria, December, 1998.

9. International Atomic Energy Agency: "Strengthening of Agency Safeguards: The Provision and Use of Design Information," IAEA Board of Governors Report \# GOV/2554/Attachment 2, (Revision 2), April, 1992.

10. International Atomic Energy Agency, Department of Safeguards: "New Safeguards Equipment Systems: Teaming IAEA Inspectors with Technology," IAEA pamphlet, Vienna, Austria, 2002.

11. International Atomic Energy Agency, Department of Safeguards: Safeguards Techniques and Equipment, Vienna, Austria, 2003. 